\title{
BULGARIAN ACADEMY OF SCIENCES
}

CYBERNETICS AND INFORMATION TECHNOLOGIES • Volume 16, No 1

Sofia $\bullet 2016$

Print ISSN: 1311-9702; Online ISSN: 1314-4081

DOI: $10.1515 /$ cait-2016-0003

\section{Comprehensive Performance Evaluation Strategy for Communication Networks Selection in Smart Grid}

\author{
Min Xiang ${ }^{1}$, Haolin Huang ${ }^{1}$, Chuan He ${ }^{1}$, Rui Li ${ }^{1}$, Lingkang Zeng ${ }^{2}$ \\ ${ }^{1}$ Key Laboratory of Industrial Internet of Things \& Networked Control, Ministry of Education, \\ Chongqing University of Posts and Telecommunications, Chongqing 400065, China \\ ${ }^{2}$ State Grid Information \& Telecommunication Co., Ltd, Beijing 102200, China \\ Emails: xiangmin@cqupt.edu.cn hhaolin0209@163.com735870667@qq.com lirui@cqupt.edu.cn \\ zenglingkang@sgepri.sgcc.com.cn
}

\begin{abstract}
Different communication networks are used in the different application environment of the smart grid. So, how to effectively select the communication networks with the optimal comprehensive performance is an important issue for the power management corporations. A novel comprehensive performance evaluation based on Exponential Scale Analytic Hierarchy Process (ESAHP) and Grey Analytic Hierarchy Process (GAHP) for the communication networks selection is proposed in the electricity information acquisition system. The ESAHP is used to calculate the weight of each communication performance index and the economic performance index, and the GAHP is adopted to evaluate the economic cost of the different communication modes. The optimal comprehensive communication model can be selected by comprehensively comparing the communication performance and the economic cost. The test results show that the assessment model can effectively evaluate the comprehensive performance of the different communication networks selection in the electricity information acquisition system of the smart grid.
\end{abstract}

Keywords: Smart grid, comprehensive performance evaluation strategy, communication networks, exponential scale analytic hierarchy process, grey analytic hierarchy process.

\section{Introduction}

The electricity consumption is increased dramatically with the rapid development of Chinese economy. The low efficiency and the operation difficulty of the traditional manual meter reading method can not meet the power system reforms and the modern meter reading requirements [1]. With the rapid development of the smart grid technology and the communication technology, more and more communication networks are used in the electricity information acquisition system of the smart grid $[2,3]$. The full coverage, full acquisition and full fee control model of the smart 
electricity information acquisition system is a basic function in the smart grid, which realizes the automatic meter reading and the automatic fare deduction. Thus, the smart electricity information acquisition system can provide convenience between the power management enterprise and the terminal users [4].

The communication link is a very important part between the main management station and the acquisition terminal device, and it is one of the key roles in the smart grid. In recent years, there are a variety of local communication networks used in the smart electricity information acquisition system, such as Power Line carrier Communication (PLC), RS-485 communication and Short-range Wireless Communication (SWC) [5]. PLC technology is a means of communication which uses the existing $380 \mathrm{~V} / 220 \mathrm{~V}$ low voltage power line infrastructure for the information transmitting without rebuilding the network. However, the harmonic noise and pulse noise interferences are inherently present in the PLC environment, so the quality of the communication is very poor [6]. RS-485 communication has good anti-interference, long transmission distance, low cost, but it has the disadvantage of the poor adaptability and the weak self-protection [7]. The short-range wireless communication network is convenient, low power consumption and low cost. However, it is easy to be interfered by the other microwave noises and its transmission speed is very low, so the communication performance is not reliable [8]. In addition, the construction cost and the maintenance cost are different among PLC, RS-485 and SWC. It is obvious that each kind of the above communication methods has its own advantages and disadvantages in the communication performance and the economic performance. Before constructing the communication networks in the electricity information acquisition system, the relevant power departments must comprehensively analyse multi-factor for selecting the optimal communication mode with high cost-performance. However, it is difficult to formulate unified evaluation criteria because of the measurable and non-measurable, tangible and intangible, quantitative and qualitative factors of the communication networks in the electricity information acquisition system. So, how to effectively evaluate the comprehensive performance and choose one or hybrid appropriate communication networks used in smart electricity information acquisition system is one of the important issues concerned by the power management departments [9-10].

At present, there is little in-depth and the specific research about the costperformance evaluation algorithm for the different communication methods in the smart electricity information acquisition system. Analytic Hierarchy Process (AHP) [11] is mainly used to solve the complex multi-criteria decision-making [12]. In general, AHP is used to decompose the decision-making process into a hierarchical structure, assuming that the relationships of criteria in different levels are independent [13]. Fuzzy AHP (FAHP) is mainly used to handle uncertainty in linguistic judgment [14]. FAHP has been proposed to solve various multi-criteria decision-making problems where trapezoidal type-1 fuzzy sets were utilized in defining decisionmakers' linguistic judgment [15]. In recent years, many researches about AHP have been proposed to solve the engineering application problems. In Ref [16], the AHP algorithm was used to identify the most relevant mobile services for consumers and the factors driving the adoption. U fuk Ce be ci [17] proposed that the FAHP was 
used to compare enterprise resource planning system in a textile manufacturing company.

In the electricity information acquisition system, there are many different communication performance parameters and the different economic cost, the traditional method is difficult to formulate the evaluation criteria for the comprehensive performance of the communication networks. In order to improve the communication performance and reduce the economic cost of the communication networks in the electricity information acquisition system, a comprehensive performance evaluation strategy for the different communication networks is proposed in this paper. The weight of communication performance and economic performance of each communication method is evaluated with Exponential Scale Analytic Hierarchy Process (ESAHP) and the economy of each communication method is analyzed with Grey Analytic Hierarchy Process (GAHP). The evaluation result can offer a helpful reference to the decision-making for the communication networks selection in the construction of the smart electricity information acquisition system.

\section{Model of electricity information acquisition system}

The electricity information acquisition system is used to automatically collect and manage the power users' electricity information. Furthermore, it can also implement the real-time monitoring of the anomaly measurement and the power quality, the information promulgation, the distributed energy monitoring and the information exchange with the smart electrical equipment, etc. The architecture of the electricity information acquisition system is shown in Fig. 1.

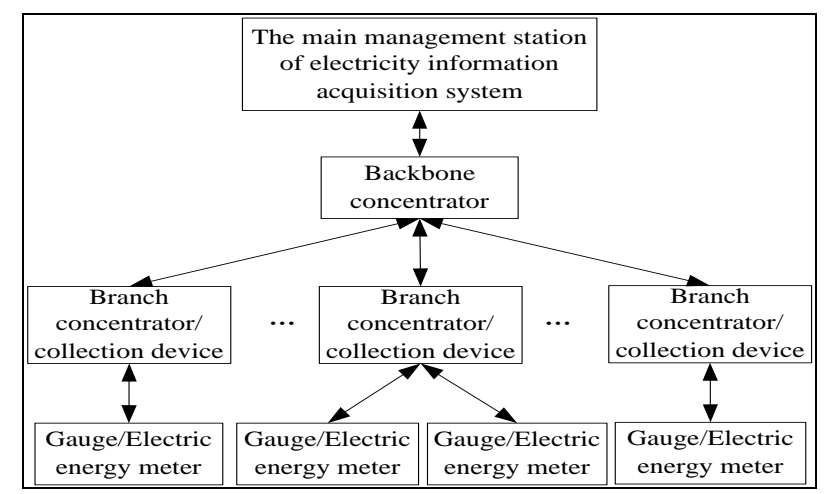

Fig. 1. The architecture of the electricity information acquisition system

In Fig. 1, the communication link between the backbone concentrator and the electric energy meter is called the local communication. In different practical application environments, a single communication mode is difficult to ensure communication reliability and reduce the economic cost. Thus, the different local communication modes would be selected in different application environments. In the electricity information acquisition system, the communication reliability and the economic cost of the local communication networks are the mainly concerned 
contents. We designed a novel comprehensive cost-performance evaluation algorithm used to select one or hybrid communication modes for the local communication networks.

\section{Comprehensive performance evaluation strategy}

There is no direct correlation between the communication performance and the economic cost, so the communication performance and the economic cost of each communication mode can be separately tested and assessed. And the ratio of the communication performance and the economic performance can be defined as the comprehensive performance of each communication mode. During analyzing the communication performance, the values of the main communication parameters can be gained through the actual test according to the existing application environments or by the recommendations the equipment manufacturers formed and standards of State Gird. ESAHP is used to calculate the weight of communication performance after the values of the main communication parameters being gained. The parameters of the economic performance are difficult to be quantified, so the qualitative factors such as high cost, middle cost, low cost are used to evaluate the economic cost of the communication networks in the electricity information acquisition system. For this reason, GAHP is used to analyse the economic cost for the different communication modes. Combine ESAHP with GAHP, can be described the main implementation steps of our

\section{Evaluation algorithm}

Step 1. A comprehensive communication performance hierarchy diagram and an economic cost hierarchy diagram are respectively established for the electricity information acquisition system.

Step 2. The initial judgment matrix is constructed according to the relative importance among the indexes, and then the exponent judgment matrix is calculated with the initial judgment matrix.

Step 3. The consistency test of the largest eigenvalue is analyzed, and only the consistency meets the requirement ruled by ESAHP, the relative importance judgment matrix among the indexes is valid, and the eigenvector corresponding to the largest eigenvalue is gained so as to get the weights of performance index. Otherwise, the operating processes must be returned to Step 2 and the initial judgment matrix must be reconstructed.

Step 4. For the communication performance, the evaluation values were calculated by actual test. Then the comprehensive values of the indexes are calculated by counting the weights of communication performance indexes with the evaluation values.

Step 5. For the economic performance, the economic cost evaluation values were calculated by GAHP. Then the comprehensive values of the indexes are calculated by counting the weights of economic performance indexes with the economic cost evaluation values.

Step 6. The comprehensive cost-performance evaluation is gained by analysing the ratio of the communication performance and the economic performance. 
3.1. Communication performance evaluation for the different communication networks

The communication performance of the electricity information acquisition system mainly focuses on two aspects. Firstly, the basic communication performance parameters which can be measured for any communication mode include the transmission rate, the transmission distance and the packet loss rate. Secondly, the business communication performance parameters include the single acquisition success rate, the cycle acquisition success rate, the time of the single-point meter reading and the time of polling meter reading. The communication performance is divided into three layers. The hierarchical chart of the communication performance indexes is shown in Fig. 2.

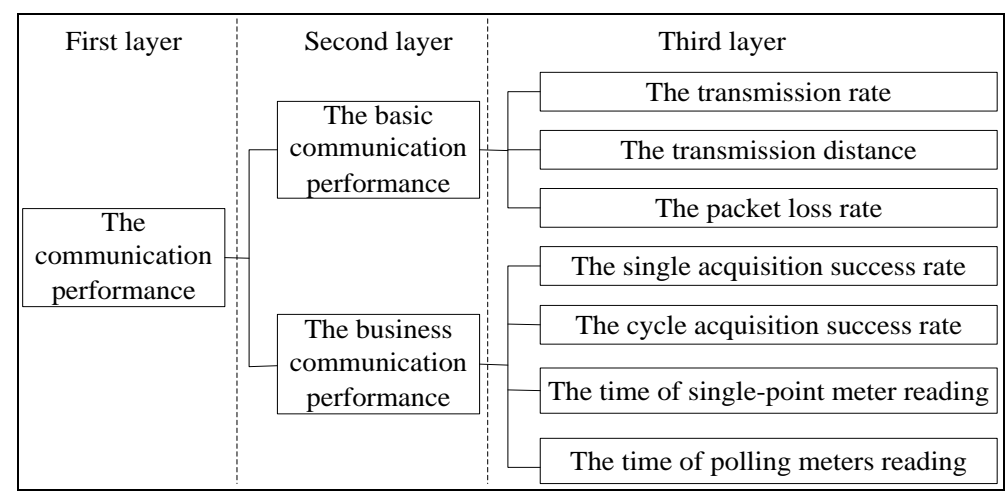

Fig. 2. The hierarchical chart of communication performance parameters

In order to simplify description for the different communication mode such as PLC, RS-485 and SWC, the different value of the parameter $k=1,2, \ldots$ is used to denote the different communication mode. In the following description, the symbol for SWC denotes $k=1$, the symbol for PLC denotes $k=2$, and symbol for RS-485 denotes $k=3$.

According to the theory of ESAHP and the hierarchical chart of the communication performance indexes, the assessment value $\left(m_{i j}\right)$ is given by experts according to the paired comparison of the relative importance among these parameters in third layer. And then, the initial judgment matrix $M[n]$ can be established as

$$
M[n]=\left[\begin{array}{cccccc}
m_{11} & m_{12} & \ldots & m_{1 j} & \ldots & m_{1 n} \\
m_{21} & m_{22} & \ldots & m_{2 j} & \ldots & m_{2 n} \\
\ldots & \ldots & \ldots & \ldots & \ldots & \ldots \\
m_{i 1} & m_{i 2} & \ldots & m_{i j} & \ldots & m_{i n} \\
\ldots & \ldots & \ldots & \ldots & \ldots & \ldots \\
m_{n 1} & m_{n 2} & \ldots & m_{n j} & \ldots & m_{n n}
\end{array}\right] .
$$

Here $i=1,2, \ldots, n, j=1,2, \ldots, n$, and $n$ denotes the number of the indexes. The assessment value $m_{i j}$ denotes the relative importance of $m_{i}$ and $m_{j}$ shown in 
Fig. 2. These pair-wise comparisons yield a opposite $n \times n$ matrix $M[n]$, where $m_{i j}=0(i=j)$ and $m_{i j}=-m_{j i}(i \neq j)$.

In the same area, the relative importance judgment matrix of any communication mode should be equal. Thus, in the electricity information acquisition system $M[\mathrm{SWC}]=M[\mathrm{PLC}]=M[\mathrm{RS}-485]$.

In the practical engineering application, the values $m_{i j}$ of the relative importance of each layer's communication performance indexes are generally given by the experts. In the initial judgment matrix, the initial assessment value is set to zero when the value of the relative importance of any two performance parameters is equal. So, the values in the exponent judgment matrix were set to 1 when the value of the relative importance of the two performance parameters is equal.

In our work, the relative importance grades between any two elements $(i, j)$ is divided into nine grades. The relative importance grades of any two elements $(i, j)$ are shown in Table 1.

Table 1 . The relative importance grades of any two elements

\begin{tabular}{|c|l|}
\hline Grade $\left(m_{i j}\right)$ & $m_{i}$ and $m_{j}$ respectively denote the importance of the two elements $(i, j)$ \\
\hline 0 & $m_{i}=m_{j}$ \\
\hline 1 & $m_{i}$ is slightly important than $m_{j}$ \\
\hline 2 & $m_{i}$ is important than $m_{j}$ \\
\hline 3 & $m_{i}$ is more important than $m_{j}$ \\
\hline 4 & $m_{i}$ is obviously important than $m_{j}$ \\
\hline 5 & $m_{i}$ is very important than $m_{j}$ \\
\hline 6 & $m_{i}$ is strongly important than $m_{j}$ \\
\hline 7 & $m_{i}$ is absolutely more important than $m_{j}$ \\
\hline 8 & $m_{i}$ is extremely more important than $m_{j}$ \\
\hline$m_{j i}$ & $\begin{array}{l}\text { If the value of the relative importance between } m_{i} \text { and } m_{j} \text { is } m_{i j} \text {, then the value of } \\
\text { the relative importance between } m_{j} \text { and } m_{i} \text { meets } m_{j i}=-m_{i j}\end{array}$ \\
\hline
\end{tabular}

The importance degree $(\alpha)$ is a very important parameter of ESAHP, and it denotes the size difference between the two adjacent relative importance grades [18]. In our work, we divide the importance degree into nine grades, $\sqrt[8]{9}=1.316$, so $\alpha$ is set to 1.316 , and the exponent judgment matrix of the communication performance can be denoted according to the initial judgment matrix:

$$
A[n]=\alpha^{M[n]} \text {. }
$$

3.1.1. The weight of the communication performance parameter and the consistency

In Fig. 2, the weights of communication performance are used to denote the proportion of each communication performance indexes in the current layer. Let $\lambda_{\max }$ be the maximal eigenvalue of the matrix $A[n]$, and let $v[n]=[v(1), v(2), \cdots, v(n)]$ be 
the eigenvector corresponding to $\lambda_{\max }$. The eigenvectors of weights $\omega[n]=[\omega(1), \omega(2), \cdots, \omega(n)]$ can be calculated by

$$
\omega(i)=v(i) / \sum_{i=1}^{n} v(i)
$$

The consistency is used to evaluate the availability of the exponent judgment matrix $A[n][19]$. In order to evaluate the consistency of the matrix $A[n]$, the maximal eigenvalue of the exponent judgment matrix and its corresponding eigenvectors are firstly calculated with (2) and (3), and the Consistency Ratio (CR) can be calculated with

$$
\left\{\begin{array}{l}
\mathrm{CR}=\mathrm{CI} / \mathrm{RI}, \\
\mathrm{CI}=\left(\lambda_{\max }-n\right) /(n-1), \quad n \geq 3,
\end{array}\right.
$$

where the Consistency Index (CI) depends on the maximal eigenvalue $\lambda_{\max }$ and the order of the matrix $A[n]$, and the values of the average consistency index (RI) are shown in Table 2.

Table 2 . The values of the average consistency index RI $(n \geq 3)$

\begin{tabular}{|c|c|c|c|c|c|c|c|}
\hline$n$ & 3 & 4 & 5 & 6 & 7 & 8 & 9 \\
\hline RI & 0.58 & 0.9 & 1.12 & 1.24 & 1.32 & 1.41 & 1.45 \\
\hline
\end{tabular}

If the consistency ratio calculated with (4) can meet the requirement $(\mathrm{CR}<0.1)$, then the initial judgment matrix $M[n]$ is acceptable. Otherwise (CR $\geq 0.1)$, the initial judgment matrix $M[n]$ should be revised.

Combine with (1), (2), (3) and (4), the weight of each performance parameter of the third layer shown in Fig. 1 can be calculated with the same method.

In the electricity information acquisition systems, the proportion of the basic communication performance and business communication performance in the second layer were given by experts.

\subsubsection{Evaluation of the comprehensive communication performance index}

The evaluation of the comprehensive communication performance index $f(k)$ should comprehensively analyse the weights $(\omega(i))$ of communication performance indexes and the actual communication performance parameters $\left(p_{i}(k)\right) . f(k)$ can be calculated with

$$
f(k)=\sum_{i=1}^{n}\left(p_{i}(k) \times \omega(i)\right),
$$

where $k$ denotes a designated communication mode such as PLC, RS-485 and SWC; the parameter $p_{i}(k)$ is used to describe the ratio of the actual Values $\left(\mathrm{Va}_{i}(k)\right)$ of the communication performance parameter to the reference Value $\left(\operatorname{Vr}_{i}(k)\right)$ of the recommendations or the professional standard formed by State Gird or the relevant international organizations. In the practical engineering application, the engineers always wish that the expected Values $\left(\operatorname{Ve}_{i}(k)\right)$ of some parameters such as the transmission distance are larger than the reference values but some other expected 
values such as the packet loss rate are less than the reference values. So the computational formula of $p_{i}(k)$ can be denoted as

$$
p_{i}(k)=\left\{\begin{array}{l}
\frac{\operatorname{Va}_{i}(k)}{\operatorname{Vr}_{i}(k)} \quad \text { if } \operatorname{Ve}_{i}(k)>\operatorname{Vr}_{i}(k) \text { and } \operatorname{Va}_{i}(k)<\operatorname{Vr}_{i}(k), \\
\text { if } \mathrm{Ve}_{i}(k)>\operatorname{Vr}_{i}(k) \text { and } \operatorname{Va}_{i}(k) \geq \operatorname{Vr}_{i}(k), \\
\text { or } \text { if } \operatorname{Ve}_{i}(k)<\operatorname{Vr}_{i}(k) \text { and } \operatorname{Va}_{i}(k) \leq \operatorname{Vr}_{i}(k), \\
\frac{\mathrm{Vr}_{i}(k)}{\operatorname{Va}_{i}(k)} \text { if } \operatorname{Ve}_{i}(k)<\operatorname{Vr}_{i}(k) \text { and } \operatorname{Va}_{i}(k)>\operatorname{Vr}_{i}(k) .
\end{array}\right.
$$

According to (3), (5) and (6), the comprehensive communication performance index $f(k)$ of each communication mode can be gained.

\subsection{Economic cost evaluation for the different communication modes}

\subsubsection{Economic cost indicator}

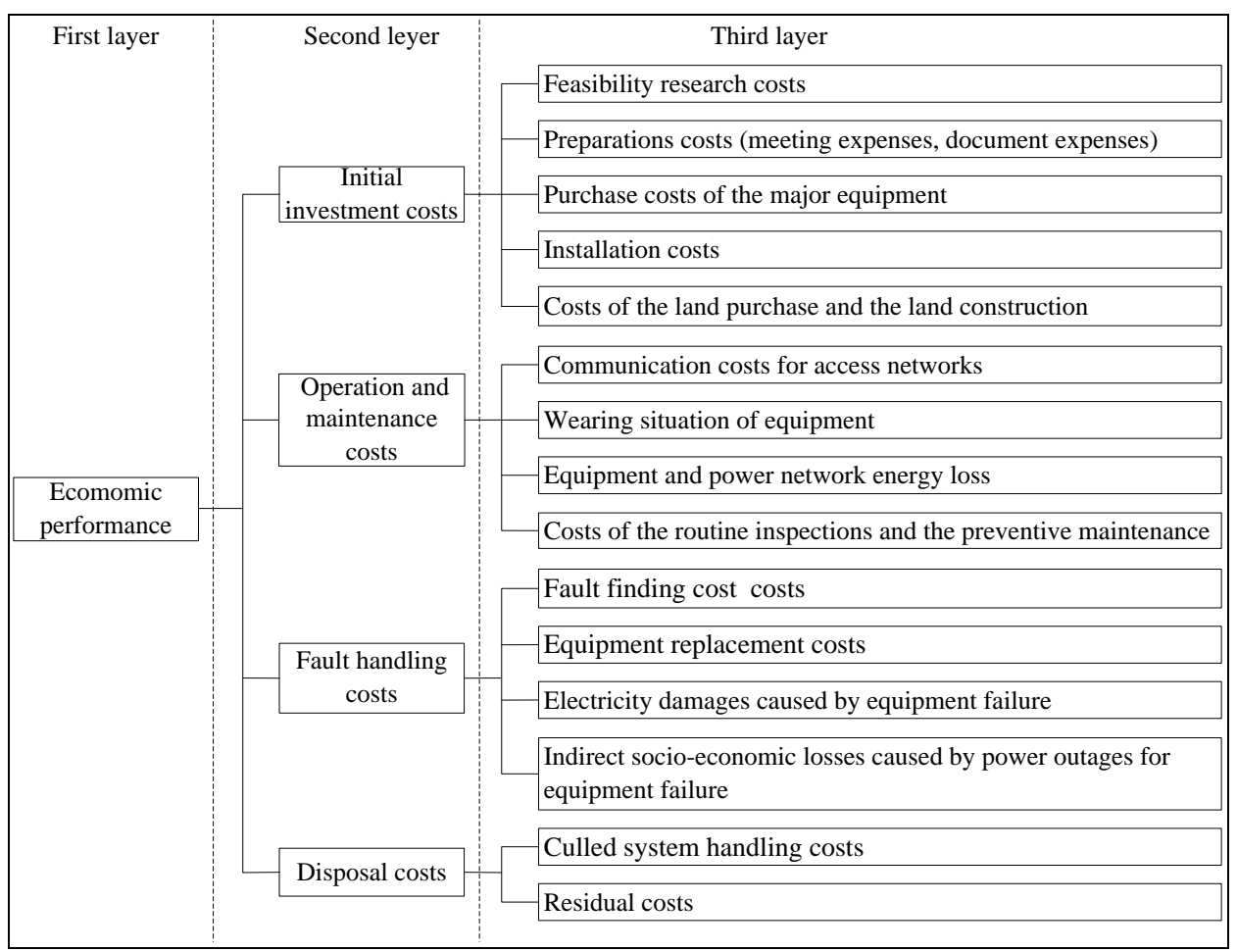

Fig. 3. Economic cost indexes system

At present, many economic cost evaluations are mainly focused on the initial investment costs consisted of the communication networks pre-construction and the initial commissioning for the smart electricity information acquisition system. However, after the communication networks of electricity information acquisition system are constructed, the operation and maintenance costs, the fault handling costs and the disposal costs are concerned by many power management corporations. In 
our research work, Life Cycle Cost (LCC) of the communication networks used in electricity information acquisition system is proposed, which includes the initial investment costs, the operation and maintenance costs, the fault handling costs and the disposal costs. The specific economic indexes system is shown in Fig. 3. It is divided into three layers. The first layer is the ultimate target of the economic evaluation. The second layer reflects the different aspects of the first layer, and the evaluation indexes of this layer are denoted as $Q=[Q(1), Q(2), Q(3), Q(4)]$. And the items of the third layer are the specific cost indexes.

\subsubsection{Weights of the economic cost parameters}

According to the theory of ESAHP and the hierarchical chart of the economic cost indexes, the initial judgement matrix $M$ of the second layer is given according to the paired comparison of the relative importance among these parameters which are in the second layer shown in Fig. 3. The initial judgment matrixes of the third layer are composed of four parts $(M[Q(1)], M[Q(2)], M[Q(3)], M[Q(4)])$, and each part is given according to the paired comparison of the relative importance among the parameters which are in its own part. And then, the weights $\omega$ of the economic cost indexes located in the second layer and third layer shown in Fig. 3 can be calculated with similar method described in calculating the weights of the communication performance indexes.

\subsubsection{Experts assessment matrix of the economic indexes}

The initial assessment values of the approximate economic cost are usually given by the experts according to their experience and understanding for the project, and the values are used to quantize the economic cost. In order to facilitate assessment, the initial assessment values in our research work are qualitatively divided into 9 grades with symbol $g$ from the lowest cost $(g=1)$ to the highest cost $(g=9)$. In the large scale electricity information acquisition system, the economic cost is difficult to be accurately quantized or classified, so the analytic method based on the grey level is used to describe the economic cost. For the description convenience, let $k$ be the grey scale, and there are five grey scales in our assessment mechanism. The correlative rules between the initial assessment values, the cost levels and the grey level are defined as Table 3.

Table 3 . The correlative rules between the initial assessment values and the grey scale

\begin{tabular}{|c|c|c|c|c|c|}
\hline Assessment value & $g \leq 2$ & $2<g \leq 4$ & $4<g \leq 6$ & $6<g \leq 8$ & $8<g \leq 10$ \\
\hline Grey scale & lowest & lower & moderate & higher & highest \\
\hline$\kappa$ & 5 & 4 & 3 & 2 & 1 \\
\hline
\end{tabular}

Let $v, v=1,2, \cdots, m$, be the number of the experts that take part in evaluating the economic indexes. In Fig. 3, there are fowr evaluated contents in the second layer. The expert evaluation sample matrix can be denoted as

$$
\left\{\begin{array}{l}
Q(i)=q_{j \times v}, \quad i=1,2,3,4, \\
Q=[Q(1), Q(2), Q(3), Q(4)]^{\mathrm{T}},
\end{array}\right.
$$


where $i$ is the number of the indexes located in the second layer of the economic indicator system; $j$ is the number of the parameters of the second layer indexes $i$; and $q_{j \times v}$ denotes the evaluation values of economic cost parameters given by the No $v$ expert.

\subsubsection{Evaluation grey scales and the whitening weight function}

The grey values reflect grey scales of project costs, and it is related with the grey level $\kappa$ which indicates the cost level of the corresponding index. According to Table 3 and (7), the whitening weight function [20] for the different grey scales can be expressed as follows.

The first grey scale $(\kappa=1)$ is related with the highest cost and its grey value meets $g \in[0,8,+\infty]$, and the whitening weight function can be expressed as

$$
f_{1}(Q(i))=\left\{\begin{array}{l}
q_{j \times v} / 8, \quad 0<q_{j \times v}<8, \\
1, \quad q_{j \times v} \geq 8, \\
0, \quad q_{j \times v} \leq 0 .
\end{array}\right.
$$

The second grey scale $(\kappa=2)$ is related with the higher cost and its grey value meets $g \in[0,8,16]$, and the whitening weight function can be expressed as

$$
f_{2}(Q(i))=\left\{\begin{array}{l}
q_{j \times v} / 8, \quad 0<q_{j \times v}<8, \\
\left(16-q_{j \times v}\right) / 8, \quad 8 \leq q_{j \times v}<16, \\
0, \quad q_{j \times v} \leq 0 \text { or } q_{j \times v} \geq 16 .
\end{array}\right.
$$

The third grey scale $(\kappa=3)$ is related with the appropriate cost and its grey value meets $g \in[0,6,12]$, and the whitening weight function can be expressed as

$$
f_{3}(Q(i))=\left\{\begin{array}{l}
q_{j \times \nu} / 6, \quad 0<q_{j \times v}<6, \\
2-q_{j \times v} / 6, \quad 6 \leq q_{j \times v}<12, \\
0, \quad q_{j \times v} \leq 0 \text { or } q_{j \times v} \geq 12 .
\end{array}\right.
$$

The fourth grey scale $(\kappa=4)$ is related with the lower cost and its grey value meets $g \in[0,4,8]$, and the whitening weight function can be expressed as

$$
f_{4}(Q(i))=\left\{\begin{array}{l}
q_{j \times v} / 4, \quad 0<q_{j \times v}<4, \\
2-q_{j \times v} / 4, \quad 4 \leq q_{j \times v}<8, \\
0, \quad q_{j \times v} \leq 0 \text { or } q_{j \times v} \geq 8 .
\end{array}\right.
$$

The fifth grey scale $(\kappa=5)$ is related with the lowest cost and its grey value meets $g \in[0,2,4]$, and the whitening weight function can be expressed as

$$
f_{5}(Q(i))=\left\{\begin{array}{l}
1, \quad 0<q_{j \times v} \leq 2, \\
2-q_{j \times v} / 2, \quad 2<q_{j \times v} \leq 4, \\
0, \quad q_{j \times v} \leq 0 \text { or } q_{j \times v}>4 .
\end{array}\right.
$$




\subsubsection{Grey assessment matrix}

The grey evaluation weight $r_{i v}(k), k=1,2,3,4,5$, of the index $q_{j \times v}$ of the expert evaluation matrix under each grey scale can be obtained by the whitening weight function

$$
r_{i v}(\kappa)=\frac{\sum_{v=1}^{m} f_{\kappa}(Q(i))}{\sum_{\kappa=1}^{5}\left(\sum_{v=1}^{m} f_{\kappa}(Q(i))\right)} .
$$

Then the grey assessment matrix $R_{i}=\left[r_{i v}(1), r_{i v}(2), r_{i v}(3), r_{i v}(4), r_{i v}(5)\right]$ can be used to express the second layer index $Q(i)$.

\subsubsection{Comprehensive economic evaluation}

The grey evaluation for the second layer index $Q(i)$ can be calculated with:

$$
B[Q(i)]=\omega_{i} \times R_{i}(\mathrm{i}=1,2,3,4) .
$$

In this equation, $\omega_{i}$ represents the weights of the third layer indexes under the second layer indexes $Q(i)$. So the grey matrix of the economic evaluation and the comprehensive indexes of the first layer shown in Fig. 3 can be denoted as

$$
\left\{\begin{array}{l}
T=(B[Q(1)], B[Q(2)], B[Q(3)], B[Q(4)])^{\mathrm{T}}, \\
B=\omega \times T,
\end{array}\right.
$$

where $\omega$ represents the weight of the second layer indexes, and $T$ is the total grey evaluation matrix of the second layer.

The grey scale of the assessment value is $D=(9,7,5,3,1)$. The comprehensive economic evaluation can be obtained with

$$
C(k)=B \times D^{\mathrm{T}},
$$

where $k=1,2, \cdots$ is used to denote the different communication mode, and $C(k)$ denotes the comprehensive economic cost of the communication mode $k$.

\subsection{Comprehensive performance value}

Obvious, the comprehensive performance of the communication networks should have high communication performance and low economic cost. Based on (5) and (16), the comprehensive performance evaluation model for the communication modes in the smart electricity information acquisition system can be defined as

$$
P(k)=f(k) / C(k) .
$$




\section{Numerical test and analysis}

\subsection{Communication performance evaluation}

In order to evaluate the performance of the proposed algorithm, the sampled data provided by the experts of Chongqing Electric Power CORP of China and Hubei Electric Power Test and Research Institute of China is used to analyse the costperformance of the different communication modes. In the smart electricity information acquisition system, SWC, PLC, and RS-485 are widely used for the local communications. Based on the sampled data provided by the experts, let $M[3]$ be the initial judgment matrix of the basic communication performance, and let $M$ [4] be the initial judgment matrix of the business communication performance

$$
\begin{gathered}
M[3]=M[\mathrm{SWC}]=M[\mathrm{PLC}]=M[\mathrm{RS}-485]=\left(\begin{array}{ccc}
0 & 3 & -3 \\
-3 & 0 & -3 \\
3 & 3 & 0
\end{array}\right), \\
M[4]=M[\mathrm{SWC}]=M[\mathrm{PLC}]=M[\mathrm{RS}-485]=\left(\begin{array}{cccc}
0 & 1 & -2 & 3 \\
-1 & 0 & -3 & 2 \\
2 & 3 & 0 & 0 \\
-3 & -2 & 0 & 0
\end{array}\right) .
\end{gathered}
$$

According to the above initial judgment matrixes, the ratios $\omega_{1}$ of each basic communication parameter to the basic communication performance and the ratios $\omega_{2}$ of the business communication parameter to the business communication performance weights can be calculated with (3) as follows:

$$
\left\{\begin{array}{l}
\omega_{1}=(0.3022,0.1745,0.5233), \\
\omega_{2}=(0.2707,0.2057,0.3443,0.1793) .
\end{array}\right.
$$

In order to unify each weight which denotes the ratio of each parameter to the total communication performance, the weight of the basic communication performance and the business communication performance given by experts are $(0.382,0.618)$. Thus, the weight of the basic communication parameter to the total communication performance is $\omega_{1} \times 0.382$, and the weight of the business communication parameter to the total communication performance is $\omega_{2} \times 0.618$. The weights of all communication performance were shown in Table 4 .

Table 4. Weights of the communication performance

\begin{tabular}{|l|l|l|}
\hline \multicolumn{2}{|c|}{ Communication performance } & Weights \\
\hline \multirow{4}{*}{ Basic communication performance } & transmission rate & 0.1154 \\
\cline { 2 - 3 } & transmission distance & 0.0667 \\
\cline { 2 - 3 } & packet loss rate & 0.1999 \\
\hline \multirow{3}{*}{$\begin{array}{l}\text { Business communication } \\
\text { performance }\end{array}$} & one acquisition success rate & 0.1673 \\
\cline { 2 - 3 } & cycle acquisition success rate & 0.1271 \\
\cline { 2 - 3 } & $\begin{array}{l}\text { single-point transcribes meters time of the } \\
\text { concentrator }\end{array}$ & 0.2128 \\
\cline { 2 - 3 } & polling transcribe meters time of the concentrator & 0.1108 \\
\hline
\end{tabular}


The measured data of the communication performance indexes gained from the actual running system is shown in Table 5. Based on (4), (5) and (6), the calculated results of the communication performance evaluation for the different communication modes are respective $f(\mathrm{SWC})=0.9864, \quad f(\mathrm{PLC})=0.9930$, $f(\mathrm{RS}-485)=0.9984$.

Table 5. Recommendation values of the communication performance indexes

\begin{tabular}{|c|c|c|c|c|c|c|c|c|}
\hline \multirow{2}{*}{\multicolumn{2}{|c|}{ Indexes }} & \multirow[b]{2}{*}{$\begin{array}{l}\text { Refe-rence } \\
\text { value }\end{array}$} & \multicolumn{2}{|c|}{ SWC } & \multicolumn{2}{|c|}{ PLC } & \multicolumn{2}{|c|}{ RS-485 } \\
\hline & & & $\begin{array}{l}\text { Mea- } \\
\text { sured } \\
\text { data }\end{array}$ & $\begin{array}{l}\text { Perfor- } \\
\text { mance } \\
\text { value }\end{array}$ & $\begin{array}{c}\text { Mea- } \\
\text { sured } \\
\text { data }\end{array}$ & $\begin{array}{c}\text { Perfor- } \\
\text { mance } \\
\text { value }\end{array}$ & $\begin{array}{c}\text { Mea- } \\
\text { sured } \\
\text { data }\end{array}$ & $\begin{array}{c}\text { Perfor- } \\
\text { mance } \\
\text { value }\end{array}$ \\
\hline \multirow{3}{*}{$\begin{array}{c}\text { Basic } \\
\text { communi- } \\
\text { cation } \\
\text { perfor- } \\
\text { mance }\end{array}$} & $\begin{array}{l}\text { Trans- } \\
\text { mission } \\
\text { rate }\end{array}$ & $\begin{array}{l}250 \mathrm{Kbps} / \\
2.4 \mathrm{Kbps} / \\
600 \mathrm{Kbps}\end{array}$ & $\begin{array}{c}250 \\
\text { Kbps }\end{array}$ & 1 & $\begin{array}{c}2.4 \\
\text { Kbps }\end{array}$ & 1.0000 & $\begin{array}{c}600 \\
\text { Kbps }\end{array}$ & 1.0000 \\
\hline & $\begin{array}{l}\text { Trans- } \\
\text { mission } \\
\text { distance }\end{array}$ & $\begin{array}{l}150 \mathrm{~m} / \\
200 \mathrm{~m} / \\
200 \mathrm{~m}\end{array}$ & 135 & 0.9000 & 190 & 0.9500 & 200 & 1.0000 \\
\hline & $\begin{array}{l}\text { Packet } \\
\text { loss rate }\end{array}$ & $\begin{array}{l}10^{-5} / \\
10^{-5} / \\
10^{-9}\end{array}$ & $2 \times 10^{-6}$ & 1 & $1 \times 10^{-6}$ & 1 & 0 & 1.0000 \\
\hline \multirow{4}{*}{$\begin{array}{c}\text { Business } \\
\text { communi- } \\
\text { cation } \\
\text { perfor- } \\
\text { mance }\end{array}$} & $\begin{array}{c}\text { One } \\
\text { acquisi- } \\
\text { tion } \\
\text { success } \\
\text { rate }\end{array}$ & $100 \%$ & $96.8 \%$ & 0.9680 & $98.2 \%$ & 0.9820 & $99.2 \%$ & 0.9920 \\
\hline & $\begin{array}{l}\text { Cycle } \\
\text { acquisi- } \\
\text { tion } \\
\text { success } \\
\text { rate }\end{array}$ & $100 \%$ & $98.8 \%$ & 0.9880 & $99.5 \%$ & 0.9950 & $99.8 \%$ & 0.9980 \\
\hline & $\begin{array}{l}\text { Single- } \\
\text { point } \\
\text { trans- } \\
\text { cribes } \\
\text { meters } \\
\text { time of } \\
\text { the } \\
\text { concent- } \\
\text { rator }\end{array}$ & $\begin{array}{c}5 \mathrm{~s} / \\
10 \mathrm{~s} / \\
5 \mathrm{~s}\end{array}$ & $3.88 \mathrm{~s}$ & 1 & $6.6 \mathrm{~s}$ & 1 & $3.89 \mathrm{~s}$ & 1 \\
\hline & $\begin{array}{l}\text { Polling } \\
\text { trans- } \\
\text { cribe } \\
\text { meters } \\
\text { time of } \\
\text { the } \\
\text { concent- } \\
\text { rator }\end{array}$ & $\begin{array}{l}10 \mathrm{~min} / \\
60 \mathrm{~min} / \\
10 \mathrm{~min}\end{array}$ & $\begin{array}{l}6.14 \\
\min \end{array}$ & 1 & $\begin{array}{l}45.5 \\
\min \end{array}$ & 1 & $\begin{array}{l}5.67 \\
\min \end{array}$ & 1 \\
\hline
\end{tabular}




\subsection{Economic cost evaluation}

\subsubsection{Weights of the economic cost parameters}

According to the sampled data by the experts and the hierarchical relation shown in Fig. 3, the initial judgment matrix $(M)$ of the second layer and the initial judgment matrixes ( $M[Q(1)], M[Q(2)], M[Q(3)], M[Q(4)])$ of the third layer can be expressed as following:

$$
\begin{gathered}
M=\left(\begin{array}{ccccc}
0 & 0 & 2 & 3 \\
0 & 0 & -3 & 3 \\
-2 & 3 & 0 & 3 \\
-3 & -3 & -3 & 0
\end{array}\right), M[Q(1)]=\left(\begin{array}{ccccc}
0 & 2 & -3 & 3 & -3 \\
-2 & 0 & 2 & 2 & -3 \\
3 & -2 & 0 & 3 & -1 \\
-3 & -2 & -3 & 0 & -3 \\
3 & 3 & 1 & 3 & 0
\end{array}\right), \\
M[Q(2)]=\left(\begin{array}{cccc}
0 & 2 & -2 & -3 \\
-2 & 0 & -3 & -2 \\
2 & 3 & 0 & -2 \\
3 & 2 & 2 & 0
\end{array}\right), M[Q(2)]=\left(\begin{array}{cccc}
0 & 2 & -2 & -3 \\
-2 & 0 & -3 & -2 \\
2 & 3 & 0 & -2 \\
3 & 2 & 2 & 0
\end{array}\right), M[Q(4)]=\left(\begin{array}{cc}
0 & -2 \\
2 & 0
\end{array}\right) .
\end{gathered}
$$

The weights of the second layer are $\omega=(0.3309,0.2339,0.3141,0.1211)$. The weights of the initial investment costs of the third layer are $\omega_{1}=(0.1799,0.1850$, $0.2556,0.0974,0.3121)$. The weights of the operation and maintenance costs of the third layer are $\omega_{2}=(0.1889,0.1464,0.2845,0.3802)$. The weights of the trouble costs of the third layer are $\omega_{3}=(0.1737,0.1087,0.2278,0.4898)$ and the weights of the disposal costs of the third layer are $\omega_{4}=(0.3660,0.6340)$.

\subsubsection{Grey assessment matrix and the economic cost evaluation}

The economic assessment is operated by five experts. The assessment values for economic indexes were given in Table 6 . The grey assessment matrix of initial investment costs of the SWC $R[Q(1)]$ can be obtained through the grey value and whitening weight function:

$$
\begin{aligned}
& R[Q(1)]=\left(\begin{array}{lllll}
0.2321 & 0.2321 & 0.2857 & 0.2143 & 0.0357 \\
0.1304 & 0.1304 & 0.1739 & 0.2609 & 0.3043 \\
0.1548 & 0.1548 & 0.2066 & 0.2903 & 0.1935 \\
0.1944 & 0.1944 & 0.2593 & 0.2778 & 0.0741 \\
0.2259 & 0.2259 & 0.2772 & 0.2349 & 0.0361
\end{array}\right), \\
& B[Q(1)]=\omega_{1} \times R[Q(1)]=(0.1948,0.1948,0.2481,0.2614,0.1306) .
\end{aligned}
$$

By the same ways, the other grey values can be calculated as following: the grey assessment matrix of operation and maintenance cost is

$$
B[Q(2)]=\omega_{2} \times R[Q(2)]=(0.2032,0.2032,0.2605,0.2633,0.0697) ;
$$

the grey assessment matrix of trouble cost is

$$
B[Q(3)]=\omega_{3} \times R[Q(3)]=(0.2017,0.2017,0.2498,0.2633,0.0836) ;
$$


the grey assessment matrix of disposal cost is

$$
B[Q(4)]=\omega_{4} \times R[Q(4)]=(0.1391,0.1391,0.1855,0.2646,0.2445) .
$$

The grey evaluation matrix of SWC $T_{\mathrm{SWC}}$ can be calculated as following:

$$
\begin{gathered}
T_{\mathrm{SWC}}=(B[Q(1)], B[Q(2)], B[Q(3)], B[Q(4)])^{\mathrm{T}}= \\
=\left(\begin{array}{lllll}
0.1948 & 0.1948 & 0.2481 & 0.2614 & 0.1306 \\
0.2033 & 0.2033 & 0.2605 & 0.2633 & 0.0697 \\
0.2017 & 0.2017 & 0.2498 & 0.2633 & 0.0836 \\
0.1391 & 0.1391 & 0.1855 & 0.2646 & 0.2445
\end{array}\right), \\
B_{\mathrm{SWC}}=\omega \times T_{\mathrm{SWC}}=(0.1922,0.1922,0.2436,0.2628,0.1154) .
\end{gathered}
$$

In our research work, let $D=(9,7,5,3,1)$. The economic evaluation of the SWC can be calculated with (16):

$$
C_{\mathrm{SWC}}=B_{\mathrm{SWC}} \times D^{\mathrm{T}}=5.1970 .
$$

The grey evaluation matrix of PLC can be calculated as

\begin{tabular}{|c|c|c|c|c|c|c|c|c|c|c|c|c|c|c|c|c|}
\hline \multirow{3}{*}{ LCC } & \multirow{3}{*}{ Economic indexes } & \multicolumn{5}{|c|}{ SWC } & \multicolumn{5}{|c|}{ PLC } & \multicolumn{5}{|c|}{ RS-485 } \\
\hline & & \# & $\#$ & \# & $\#$ & $\#$ & $\#$ & \# & \# & \# & $\#$ & $\#$ & $\#$ & \# & $\#$ & \# \\
\hline & & 1 & 2 & 3 & 4 & 5 & 1 & 2 & 3 & 4 & 5 & 1 & 2 & 3 & 4 & 5 \\
\hline \multirow{5}{*}{$\begin{array}{l}\text { Initial } \\
\text { investment } \\
\text { cost } Q_{1}\end{array}$} & $\begin{array}{c}\text { Feasibility } \\
\text { research costs }\end{array}$ & 6 & 3 & 7 & 5 & 5 & 4 & 3 & 5 & 3 & 2 & 7 & 2 & 4 & 5 & 3 \\
\hline & Preparations costs & 1 & 2 & 4 & 3 & 2 & 2 & 2 & 4 & 4 & 5 & 2 & 1 & 4 & 5 & 4 \\
\hline & $\begin{array}{c}\text { Major equipment } \\
\text { purchase costs }\end{array}$ & 4 & 3 & 5 & 2 & 2 & 5 & 5 & 4 & 4 & 3 & 7 & 5 & 9 & 5 & 6 \\
\hline & Installation costs & 6 & 3 & 5 & 3 & 4 & 3 & 3 & 2 & 4 & 5 & 6 & 7 & 5 & 5 & 2 \\
\hline & $\begin{array}{c}\text { Costs of land } \\
\text { purchase and land } \\
\text { construction }\end{array}$ & 4 & 3 & 6 & 7 & 5 & 3 & 3 & 4 & 3 & 5 & 3 & 3 & 8 & 7 & 5 \\
\hline
\end{tabular}

$$
\begin{aligned}
& T_{\mathrm{PLC}}=\left(\begin{array}{lllll}
0.1803 & 0.1803 & 0.2404 & 0.3116 & 0.1175 \\
0.1905 & 0.1905 & 0.2468 & 0.2748 & 0.0975 \\
0.1740 & 0.1740 & 0.2196 & 0.2549 & 0.1677 \\
0.1300 & 0.1300 & 0.1733 & 0.2325 & 0.3342
\end{array}\right), \\
& B_{\mathrm{PLC}}=\omega \times T_{\mathrm{PLC}}=(0.1746,0.1746,0.2272,0.2756,0.1548) \text {, } \\
& C_{\mathrm{PLC}}=B_{\mathrm{PLC}} \times D^{\mathrm{T}}=4.9112 .
\end{aligned}
$$

The grey evaluation matrix of RS-485 is calculated as

$$
\begin{gathered}
T_{\mathrm{RS}-485}=\left(\begin{array}{ccccc}
0.2358 & 0.2335 & 0.2625 & 0.2169 & 0.0814 \\
0.1999 & 0.1999 & 0.2526 & 0.2569 & 0.0906 \\
0.2111 & 0.2111 & 0.2700 & 0.2534 & 0.0544 \\
0.1265 & 0.1265 & 0.1686 & 0.2128 & 0.3656
\end{array}\right), \\
B_{\mathrm{RS}-485}=\omega \times T_{\mathrm{RS}-485}=\left(\begin{array}{ll}
0.2064,0.2056,0.2512,0.2372,0.1095
\end{array}\right), \\
C_{\mathrm{RS}-485}=B_{\mathrm{RS}-485} \times D^{\mathrm{T}}=5.3739 .
\end{gathered}
$$

Table 6. Assessment value for the economic indexes 


\begin{tabular}{|c|c|c|c|c|c|c|c|c|c|c|c|c|c|c|c|c|}
\hline \multirow{3}{*}{ LCC } & \multirow{3}{*}{ Economic indexes } & \multicolumn{5}{|c|}{ SWC } & \multicolumn{5}{|c|}{ PLC } & \multicolumn{5}{|c|}{ RS-485 } \\
\hline & & \# & \# & \# & \# & \# & \# & \# & \# & \# & \# & \# & \# & \# & \# & \# \\
\hline & & 1 & 2 & 3 & 4 & 5 & 1 & 2 & 3 & 4 & 5 & 1 & 2 & 3 & 4 & 5 \\
\hline \multirow{4}{*}{$\begin{array}{l}\text { Operation and } \\
\text { maintenance } \\
\text { cost } Q_{2}\end{array}$} & $\begin{array}{c}\text { Communication } \\
\text { costs for access } \\
\text { networks }\end{array}$ & 1 & 2 & 4 & 3 & 3 & 2 & 2 & 3 & 4 & 3 & 2 & 2 & 5 & 4 & 2 \\
\hline & $\begin{array}{l}\text { Wearing situation } \\
\text { of equipment }\end{array}$ & 7 & 3 & 6 & 4 & 3 & 5 & 4 & 3 & 5 & 6 & 7 & 4 & 8 & 6 & 7 \\
\hline & $\begin{array}{c}\text { Equipment and } \\
\text { power network } \\
\text { energy loss }\end{array}$ & 3 & 4 & 7 & 5 & 6 & 3 & 2 & 7 & 4 & 5 & 3 & 2 & 5 & 5 & 4 \\
\hline & $\begin{array}{l}\text { Costs of routine } \\
\text { inspections and } \\
\text { preventive } \\
\text { maintenance }\end{array}$ & 5 & 4 & 5 & 5 & 5 & 5 & 3 & 5 & 4 & 5 & 5 & 3 & 5 & 5 & 5 \\
\hline \multirow{4}{*}{$\begin{array}{c}\text { Trouble cost } \\
\qquad Q_{3}\end{array}$} & $\begin{array}{c}\text { Troubleshooting } \\
\text { costs }\end{array}$ & 7 & 1 & 5 & 3 & 3 & 3 & 3 & 5 & 4 & 3 & 5 & 4 & 3 & 5 & 6 \\
\hline & $\begin{array}{c}\text { Equipment } \\
\text { replacement costs }\end{array}$ & 7 & 5 & 5 & 5 & 4 & 5 & 3 & 5 & 4 & 5 & 5 & 5 & 5 & 5 & 6 \\
\hline & $\begin{array}{c}\text { Electricity } \\
\text { damages caused } \\
\text { by equipment } \\
\text { failure }\end{array}$ & 3 & 3 & 2 & 3 & 3 & 2 & 2 & 1 & 2 & 3 & 3 & 1 & 3 & 4 & 3 \\
\hline & $\begin{array}{l}\text { Socio-economic } \\
\text { losses }\end{array}$ & 7 & 5 & 4 & 5 & 4 & 7 & 5 & 3 & 2 & 4 & 7 & 5 & 4 & 5 & 6 \\
\hline \multirow{2}{*}{$\begin{array}{c}\text { Disposal cost } \\
Q_{4}\end{array}$} & $\begin{array}{l}\text { Culled system } \\
\text { handling costs }\end{array}$ & 5 & 4 & 4 & 4 & 4 & 3 & 3 & 5 & 4 & 5 & 5 & 3 & 4 & 5 & 5 \\
\hline & Residual values & 3 & 2 & 2 & 1 & 2 & 2 & 1 & 1 & 2 & 2 & 2 & 1 & 1 & 1 & 1 \\
\hline
\end{tabular}

4.3. Comprehensive performance evaluation for the different communication networks

Based on (17), the comprehensive cost-performance of the three local communication modes can be calculated as following:

$$
\begin{gathered}
p(\mathrm{SWC})=0.9864 / 5.1970=0.1898, \\
p(\mathrm{PLC})=0.9930 / 4.9112=0.2022, \\
p(\mathrm{RS}-485)=0.9984 / 5.3739=0.1858 .
\end{gathered}
$$

\subsection{Results and analysis}

According to the calculated results of the communication performances and the economic costs for the three local communication networks, the communication performance of RS-485 communication networks is the best, and the economic cost of PLC communication networks is the best, and the comprehensive performance of the PLC communication networks is the best. In Table 4, the measured data of the communication parameters is sampled from the electrical environment for residents, and the calculated results are consistent with the actual structure of the communication networks. In the practical engineering, the communication performance of SWC and PLC are seriously affected by the engineering environment. 
For example, the communication reliability of PLC networks would be sharp declined in the industrial environment for the harmonic noise and pulse noise interferences. However, there is good communication reliability when PLC networks are used in the electrical environment for residents. So, the relevant power management departments should analyse the communication networks application environment before constructing the communication networks. According to the empirical data or the actual test data and the data given by the experts, the communication performance index can be calculated with Equation (5). Obviously, in order to gain the optimal comprehensive performance communication networks, the communication performance and the economic cost of the communication mode should be fully analysed and calculated in the actual project.

\section{Conclusion}

A comprehensive performance evaluation strategy based on ESAHP and GAHP is designed for selecting an optimal communication networks in smart electricity information acquisition system. Combining ESAHP with GAHP, the communication performance and the economic cost of each communication network can be calculated, and the optimal comprehensive performance of each communication network can be gained by analysing the ratio of the communication performance to the cost performance. With our comprehensive performance evaluation strategy, a formulated unified evaluation mode can be constructed for avoiding independently analyse measurable and non-measurable, tangible and intangible, quantitative and qualitative factors of the communication networks in the electricity information acquisition system. The strategy will be helpful to evaluate the cost-performance and select an optimal communication networks for smart electricity information acquisition system.

Acknowledgments: This work was supported by Research Project of Chongqing S\&T Committee (cstc2015jcyjA40007), Science Project of State Grid Corporation of China (Key Technology Research and Application of Multi-purpose Wireless Access for Electrical Distribution Equipments, SGJSSZ00FZJS1501091), National Nature Science Fund of People's Republic of China (Project No 11372366), Chongqing Science Fund for Distinguished Young Scholars (cstc2014jcyjjq40004) and Chongqing Excellent Talents Plan for Universities.

\section{References}

1. $\mathrm{Hu}$ u, J., G. Zhu, X. Du. Electricity Information Acquisition System Application Situation and Development Trend. - Automation of Electric Power Systems, Vol. 28, 2014, No 2, pp. 131-135.

2. W a n g, W., Y. X u, M. K h a n n a. A Survey on the Communication Architectures in Smart Grid. - Computer Networks, Vol. 55, 2011, No 15, pp. 3604-3629.

3. IBM Corporation. Smart Grid Method and Model [R]. Beijing: IBM Corporation, 2010.

4. L e i, Y., J. Li, B. H o u. Power Distribution and Utilization Communication Network for Smart Grid. - Power System Technology, Vol. 35, 2011, No 12, pp. 14-19. 
5. Li, J., X. Li u. Compare with Electricity Information Acquisition Local Communication Link of Low-Voltage Power User. - Telecommunications for Electric Power System, Vol. 8, 2010, pp. 61-65.

6. W e i, X., B. W a n g, Y.-J. Ji a n g. Power Line Carrier Communication Technology and its Applications in Electric Energy Data Acquisition System. - Electrical Measurement \& Instrumentation, Vol. 47, 2010, No 7A, pp. 44-47.

7. P a n, K., J. S h e n, Z. X u. Communication Mode of Power Utilization Information Collection of Urban Residents. - Telecommunications for Electric Power System, Vol. 3, 2010, pp. 58-61.

8. T a n g, Y., X. L i u. Analysis on Micro-Power Wireless Channel Communication Network Structure of the Electricity Collection Terminal. - Electrical Measurement \& Instrumentation, Vol. 50, 2013, No 569, pp. 56-62.

9. G u n g o r, V. C., F. C. La m b e r t. A Survey on Communication Networks for Electric System Automation. - Computer Networks, Vol. 50, 2006, No 3, pp. 877-897.

10. Li, W., L. Q i u. Planning and Construction of Power Distribution Network Automation System. Telecommunications for Electric Power System, Vol. 30, 2009, No 196, pp. 5-7.

11. S a a t y, T. L. The Analytic Hierarchy Process. NewYork, McGraw Hill Company. 1980.

12. K a n g, S., J. P e n, Y. H e. Comprehensive Evaluatin of Power Quality Based on the Integration of Fuzzy Analytic Hierarchy Process With Multi-Objective Decesion-Making. - Power System Technology, Vol. 33, 2009, No 19, pp. 113-118.

13. Y u, J. R., W.-Y. S h in g. Fuzzy Analytic Hierarchy Process and Analytic Network Process: An Integrated Fuzzy Logarithmic Preference Programming. - Applied Soft Computing, Vol. 13, 2013, pp. 1792-1799.

14. H s u, Y. L., C. H. L e e, V. B. Kre n g. The Application of Fuzzy Delphi Method and Fuzzy AHP in Lubricant Regenerative Technology Selection. - Expert Systems with Applications, Vol. 37, 2010, No 1, pp. 419-425.

15. A b d u 11 a h, L., L. N a i b. A New Type-2 Fuzzy Set of Linguistic Variables for the Fuzzy Analytic Hierarchy Process. - Expert Systems with Applications, Vol. 41, 2014, pp. 3297-3305.

16. N i k o u, S., J. M e z e i. Evaluation of Mobile Services and Substantial Adoption Factors with Analytic Hierarchy Process (AHP). - Telecommunications Policy, Vol. 37, 2013, pp. 915-929.

17. C e b e c i, U. Fuzzy AHP-Based Decision Support System for Selecting ERP Systems in Textile Industry by Using Balanced Scorecard. - Expert Systems with Applications, Vol. 36, 2009, No 5, pp. 8900-8909.

18. L v, Y., Z. W e i. Kernel Function of Index Scale in AHP Scale System. - Journal of Systems Engineering, Vol. 18, 2003, No 5, pp. 452-456.

19. X u, Z., C. W e i. A Consistency Improving Method in the Analytic Hierarchy Process. - European Journal of Operational Research, Vol. 116, 1999, No 2, pp. 443-449.

20. D a i, T., B. S o n g, Z. P e n g. Substation Communication Network Condition Evaluation Based On Grey Analytic Hierarchy Process. - Engineering Journal of Wuhan University, Vol. 44, 2011, No 4, pp. 526-529. 